\section{DESALEITAMENTO DE BEZERROS HOLANDESES SUBMETIDOS A DIETAS DIFERENTES. III. OBSERVAÇŌES POST-MORTEM}

\author{
C.S.LUCCI \\ Professor Adjunto \\ Faculdade de Medicina Veterinária \\ e Zootecnia da USP \\ A.G. MORENO \\ Professor Assistente Doutor \\ Faculdade de Medicina Veterinária \\ e Zootecnia da USP \\ M. FUNADA \\ Médico Veterinário \\ S. KUBOKI \\ Médico Veterinário
}

LUCCI, C.S.; MORENO, A. G.; FUNADA, M.; KUBOKI, S. Desalei tamento de bezerros holandeses submetidos a dietas diferentes. III. Observaçōes post-mortem. Rev. Fac. Med. vet. Zootec. Univ. São Paulo, 17(1/2) : 15-17, 1980.

RESUMO: Vinte e quatro bezerros machos Holandeses P.C. foram submetidos a quatro tratamentos os quais compreendiam leite em quantidades restritas, mistura iniciadora e mais: A) ausência de volumosos; B) feno de alfafa, C) feno de capim de Rhodes e D) silagem de milho. O delineamento escolhido foj o de blocos ao acaso, e na 13 a semana de idade 22 animais foram sacrificados, para exame dos seus aparelhos digestivos. Não foram encontradas evidências que bezerros ingerindo concentrados mais volumosos apresentassem maior peso em seus aparelhos digestivos que bezerros recebendo apenas concentrados. Também não foram encontradas alteracões nas mucosas dos rumens em bezerros que não recebiam volumosos, nem problemas metabólicos que resultassem em diarréia ou timpanismo.

UNITERMOS: Bezerros, desaleitamento * Nutrição; ruminantes* .

\section{INTRODUÇÃO}

O desenvolvimento do aparelho digestivo de bezerros, pode ser controlado pela dieta obtendo-se um bezerro ruminante, no pleno sentido fisiológico da palavra, às 7-8 semanas de idade, até o caso oposto criando-se um bezerro até 4-5 meses ou mais, como pré-ruminantes, usando quantidades liberais de leite. PRESTON 11 foi quem levantou a hipótese, hoje comprovada, que o desenvolvimento do rumen depende menos da idade e mais rapidez em ingerir alimentos sólidos por parte do bezerro.

Ao comparar-se sistemas de desaleitamento com mesma quantidade de leite mas diferentes tipos de alimentos sólidos podem surgir, como variáveis não controladas, diferentes pesos de aparelhos digestivos. ROY 12 cita dados para bezerros com aproximadamente 12 semanas de idade, os quais apresentaram em dietas com leite + concentrados "adlibitum" $11 \%$ e, com leite + feno "ad-libitum" $27 \%$ de seus pesos vivos, como enchimentos dos aparelhos digestivos. WARNER, FLATT e LOOSLI ${ }^{15}$ também observaram que dietas contendo feno aumentavam o tamanho do rumen.

Não só o peso dos órgãos e conteúdos foram alvo de estudos, como características de desenvolvimento das mucosas dos rumens, traduzidas principalmente pelo comprimento das papilas. FLATT, WARNER e LOOSLI ${ }^{1}$ afirmaram que o melhor critério para medir o efeito de várias dietas sôbre o desenvolvimento do rumen seria a medição de suas papilas. Dos alimentos sólidos, os concentrados seriam os responsáveis pelo desenvolvimento dessas organelas, através de liberação de maiores quantidades de ácido butírico no interior do proventriculo (HUBER ${ }^{2}$, PEIXOTO $^{10}$ ROY $^{12}$, e, STOBO, ROY e GASTON ${ }^{13}$

Também as características dos conteúdos do rumen dizem muito sôbre a presença ou não de ruminação eficiente. SWANSON e HARRIS ${ }^{14}$ em estudos com bezerros que recebiam misturas iniciadoras e feno, sacrificou um que não ruminava e três que ruminavam, encontrando no rumen do primeiro, palha em pedaços grosseiros, poucos grãos e muito líquido, enquanto os outros apresentaram conteúdos homogêneos e finamente macerados.

Dietas com misturas iniciadoras e muito pouco ou ausência de volumosos, induziriam o aparecimento de timpanismo em maiores freqüências ( $R O Y^{12}$ ), e ainda placas e erosões da mucosa do rumen (NOLLER, DICSON e HILL ${ }^{8}$ e ROY1 2). Alguns estudos foram executados no Brasil para observação do desenvolvimento do aparelho digestivo de bezerros, sob condições padronizadas (LUCCI ${ }^{5}$, PAIVA e LUCCI $^{9}$ ). A finalidade do presente trabalho foi procurar diferenças que ocorreriam no aparelho digestivo de bezerros sob dietas diferentes, averiguando se ocorre interferência nos ganhos de peso vivo.

\section{MATERIAL E MÉTODOS}

Vinte e quatro bezerros Holandeses machos ppc, var. malhados de preto, foram dispostos em um experimento em blocos casualizados, comparando quatro tratamentos, que compreendiam além de leite em quantidades restritas até à 7 ạ semana de idadę mistura iniciadora até o máximo de 2.5 $\mathrm{kg}$ por bezerro por dia e os seguintes tratamentos: A) sem volumosos, B) com feno de alfafa, C) com feno de capim Rhodes (Chlorys gayana) e D) com silagem de milho. Maiores detalhes do manejo e alimentação estão descritos em trabalho anterior (LUCCI e Cols 6 ).

Vinte e dois dos 24 bezerros que iniciaram o experimento foram sacrificados ao atingirem a 13 ạ semana de idade todos no mesmo horário (pela manhã) sendo que não receberam, no dia do abate, as suas refeições. 
Os bezerros foram pesados e em seguida abatidos, separando-se imediatamente seus aparelhos digestivos. Comi o auxílio de ligaduras, isolaram-se rumen-retículo, omaso-abomaso e intestinos, os quais foram pesados com seus conteúdos, depois cuidadosamente esvasiados e pesados novamente.

Os conteúdos dos rumens foram examinados quanto a aspectos e odores. As mucosas mereceram especial atenção, sendo após o exame colhidas porções de $5 \mathrm{~cm}^{2}$ provenientes do saco craneal dorsal, para medição da altura das papilas, com auxilio de um paquimetro.

As carcaças foram pesadas após o abate e repesadas após 24 horas de resfriamento, quando separaram-se músculos dos ossos.

\section{RESULTADOS E DISCUSSÃo}

A tabela 1 formece dados sobre rendimentos das carcaças, pesos das musculaturas e dos fígados, para os diversos tratamentos.

Tabela 1. Rendimento das carcaças, em porcentagens, pesos das musculaturas e fígados, em quilogramos, como quadrados mínimos, para os diversos tratamentos.

\section{TRATAMENTOS}

\begin{tabular}{|c|c|c|c|c|c|}
\hline & $\mathbf{A}$ & B & C & D & CV $(\%)$ \\
\hline $\begin{array}{l}\text { Rendimentos das } \\
\text { Carcaças (\%) }\end{array}$ & 46,8 & 49.3 & 49.9 & 46,4 & 11,2 \\
\hline Musculatura (kg) & 16,3 & 23,6 & 18,0 & 23,8 & 28,7 \\
\hline Fígado $(\mathrm{kg})$ & 1,3 & 1,6 & 1,4 & 1,3 & $20,6 \%$ \\
\hline
\end{tabular}

Não houve diferenças significativas entre tratamentos para nenhuma das variáveis dispostas na Tabela 1 , sendo o coeficiente de variação elevado para musculatura e fígados. Quanto aos pesos obtidos em musculatura, em que pese a falta de significância dos dados, houve tendência de maiores valores ocorreram nos tratamentos $\mathrm{B}$ e $\mathrm{D}$, concordando com o aspecto mais desenvolvido dos animais nessas rações e melhores ganhos de peso relatados alhures (LUCCI e Cols 6 ).

A Tabela 2 tornece dados de conteúdo do rumen-reticulo, do omaso-abomaso e dos intestinos, bem como de todo o conteúdo do aparelho digestivo, sendo que o conteúdo total é fornecido também como porcentagens dos pesos vivos. Os comprimentos ou alturas das papilas são formecidas em milímetros.

Tabela 2. Conteúdo de diversas seções do aparelho gestivo, em quilogramos, conteúdo do total do aparelho digestivo como porcentagem dos pesos vivos, e altura das papilas da mucosa do rumen, em milímetros.

\section{OBSERVAÇÕES}

TRATAMENTOS

$\begin{array}{lrrrrl}\text { Conteúdo do: } & \text { A } & \text { B } & \text { C } & \text { D } & \text { CV(\%) } \\ \text { Rumen-retículo (kg) } & 6,0 & 8,4 & 6,4 & 6,9 & 33,2 \\ \text { Omaso-abo maso (kg) } & 1,3 & 1,7 & 1,0 & 1,1 & 37,2 \\ \text { Intestino (kg) } & 2,4 & 2,7 & 2,6 & 2,1 & 28,0 \\ \text { Total do aparelho (kg) } & 9,8 & 12,9 & 10,0 & 10,1 & 26,5 \\ \text { Total como porcentagem (\%) } & 14,2 & 15,8 & 15,6 & 12,0 & 23,7 \\ \text { Alturas papilas (mm) } & 4,9 & 6,0 & 5,0 & 6,2 & 19,0\end{array}$

Não ocorreram diferenças significativas $(P \leqslant 0,05)$ entre tratamentos para qualquer das variáveis contidas na Tabela 2. Estes resultado era de certa forma inesperado, pois apesar da falta de homogeneidade de alguns dados, expressa pelos coeficientes de variação, os tratamentos com volumosos C e D mostraram-se muito semelhantes ao tratamento A, sem volumosos. Os conteúdos totais dos aparellos digestivos como porcentagens dos pesos vivos dão boa idéia da proximidade entre os tratamentos, não confirmando os relatos de ROY 12 e de JAHN, CHANDLER e POLAN ${ }^{3}$. As alturas das papilas também não diferiram estatisticamente entre tratamentos, mas apresentaram tendências para valores mais altos nos tratamentos B e D, onde ocorreram ganhos de peso mais elevados, conforme trabalho anterior (LUCCI e Cols ${ }^{6}$ ). Como poderia haver a influência de alguma flutuação inesperada no consumo de alimentos durante a. última semana de vida, foi calculada a correlação entre conteúdos do rumen-retículo e a ingestão de matéria seca durante a última semana de vida igual a $r=0.03$; a correlação entre conteúdo total do aparelho digestivo e ingestão de matéria seca na última semana, igual a $r-0.23$, ambos os valores praticamente nulos. Também foram calculados coeficientes de correlação entre tempos despendidos em ingerir alimentos durante a última semana de vida, exposto em trabalho anterior (LUCCI e Cols ${ }^{7}$ ) e os enchimentos dos aparelhos digestivos de cada bezerro sendo $\mathrm{I}=0.11$, sem significado estat ístico. A correlação entre conteúdo do rumen-retículo e conteúdo totais do aparelho digestivo foi $\mathrm{r}=0,93$ ( $\mathrm{P} \leqslant$ $0,01 \%$ ), altamente significativa, sugerindo que em futuros estudos dessa natureza será suficiente coletar conteúdos do rumen-retículo apenas, aos invés do conteúdo total do aparelho digestivo, processo muito mais trabalhoso.

Os conteúdos do rumen mostraram-se sem exceção homogeneos e finamente macerados, características de um processo de ruminação bem desenvolvido segundo SWANSON e HARRIS ${ }^{14}$. Assim, todos os tratamentos foram eficientes em provocar a ruminação conforme exame às 12 semanas de idade. Não foram encontradas placas erosões ou quaisquer anomalias nas mucosas dos rumens de bezerros que não receberam volumosos, o que contradiz em parte as afirmativas de NOLLER, DICKSON HILL ${ }^{8}$ e ROY 12 , de ocorrer maior incidência dessas anomalias em dietas com poucos volumosos. Contudo, o experimento correu com um pequeno número de animais.

\section{CONCLUSÕES}

Para as condições do trabalho exposto, puderam ser tiradas as seguintes conclusões:

1. Não ocorreram diferenças entre pesos de conteúdos do rumen-retículo, omaso-abomoso, intestinos, ou conteúdos do total do aparelho digestivo, entre dietas sem volumosos e com diversos volumosos.

2. Como consequência, não ocorreram tendenciosidades, nas medidas de ganhos de peso vivo, nesta situação.

3. A correlação elevada entre conteúdo do rumen e conteúdo total do aparelho digestivo sugere a primeira medida como suficiente para servir de parametro em estudos dessa natureza.

4. Não foram encontradas placas, erosões ou quaisque I anomalias nas mucosas de bezerros que não rece. biam volumosos em suas dietas.

5. Não se encontraram diferenças estatísticas nos de senvolvimentos das papilas da mucosa do rumen para os diversos tratamentos. 
LUCCI, C.S.; MORENO, A. C.; FUNADA, M.; KUBOKI, S. Weaning of Holstein male calves with diferent diets. III. Post-mortem data. Rev. Fac. Med. vet. Zootec. Univ. S. Paulo, 17(1/2): $15-17,1980$.

SUMMARY: Twenty-four Holstein male calves were used in 4 treatments with restricted mild, calf starter and $A$ no roughage; B) alfalfa hay; C) Rhodes grass hay of D) corn silage. The experiment began at 2 nd week and at 13 th week 22 calves were slaughtered for observations upon the digestive systems. The authors did not find higher gut or rumen contents in the roughage treated animals. Also they did not find erosions or plaques in the rumen mucosas of the only concentrates fed calves. The rumen papillae growth were statistically similar in all treatments.

UNITERMS: Calves, weaning systems*, Nutrition, ruminant *

\section{REFERENCIAS BIBLIOGRĀFICAS}

1 - FLATT, W. R.; WARNER, R.G.; LOOSLI, J.K. Evaluation of several techniques used in the study of developing rumen function. Ithaca, 1959, $30 \mathrm{p}$. (Cornell University Agric. Exp. Sta.).

2 - HUBER, J.T. Symposium of calf nutrition and rearing. Development of digestive and metabolic apparatus of the calf. J. Dairy Sci., 52 (8): 1303-15, 1969.

3 - JAHN, E.; CHANDLER, P.T.; POLAN, C. E. Effects of fiber and ratio of starch to sugar on perfomance of ruminating calves. J. Dairy Sci., 38 (6): 651-6, 1955.

4 - LUCCI, C.S. Estudo sobre o efeito de diferentes niveis de fibra bruta em rações de desmama precoce de bezerros. Bol. Ind. anim., 29 (1): 67-149, 1972.

5 - LUCCI, C.S. Desaleitamento precoce de bezerros. III. Desenvolvimento do rumen. Rev. Fac. Med. Vet. Zootec. Univ. S. Paulo, 13 (2): 333-8, 1976.

6 - LUCCI, C. S. ; KUBOKI, S.; AOKI, M.I.; BORTOLETTO, Y.; J.R.B.C. ROSAS Desaleitamento de bezerros Holandeses submetidos a dietas diferentes. I. Desempenho produtivo. Rev. Fac. Med. Vet. Zootec. Univ. S.Paulo, 17 (1/2): -, 1980.

7 - LUCCI, C. S.; ROSAS, J.R.B.C.; BORTOLETTO, Y.; FUNADA, M.; AOKI, M.I. Desaleitamento de bezerros Holandeses submetidos a Dietas Diferentes. II. Observações sobre tempos de ruminação e de ingestão de alimentos. Rev. Fac. Med. Vet. Zootec. Univ. São Paulo, 17 (1/2); - , 1980.

8 - NOLLER, C. H.; DICKSON, I.A.; HILL, D.L. Value of hay rumen inoculation in an early weaning systen for dairy calves. J. Dairy Sci., 45: 197-201, 1962.

9 - PAIVA, J. A.J. \& LUCCI, C.S. Alimentação de bezerros com mistura concentrada comum mais feno de soja perene. II. Desenvolvimento dos proventriculos. Bol. Ind. anim., 29 (1): $151-9,1972$.

10 - PEIXOTO, A. M. Nutrição de ruminantes. ESALQ, 1967. (Postila curso PG Nutrição Animal e Pastagens), Piracicaba.

11 - PRESTON, T. R. Dry feeding of calves. Agriculture, 62 (10): 462-6, 1956.
12 - ROY, J.H.B. The calf. London, Farmer e Stockbreeder, 1970. v. 2:

13 - STOBO, I.J.F.; ROY, J.H.; GASTON, H. J. Rumen development in the calf. The effect of diets containing different proportions of concentrate to hay on rumen development. Brit. J. Nutr., 20: 171-88, 1966.

14 - SWANSON, E.W \& HARRIS JUNIOR, J.D. Development of rumination in the young calf. J. Dairy Sci 41 (12): 1768-76, 1958.

15 - WARNER, R.G.; FLATT, W.P.; LOOSLI, J.K. Evaluation of several techniques used in the study of developing rumen function. Dietary factors influencing the development of the ruminant stomach. J. Agric. Fd. Chem., 4 (9): 788 - 92, 1956.

Recebido para publicação em 14.08.1979 Aprovado para publicação em: 20.10.1980 